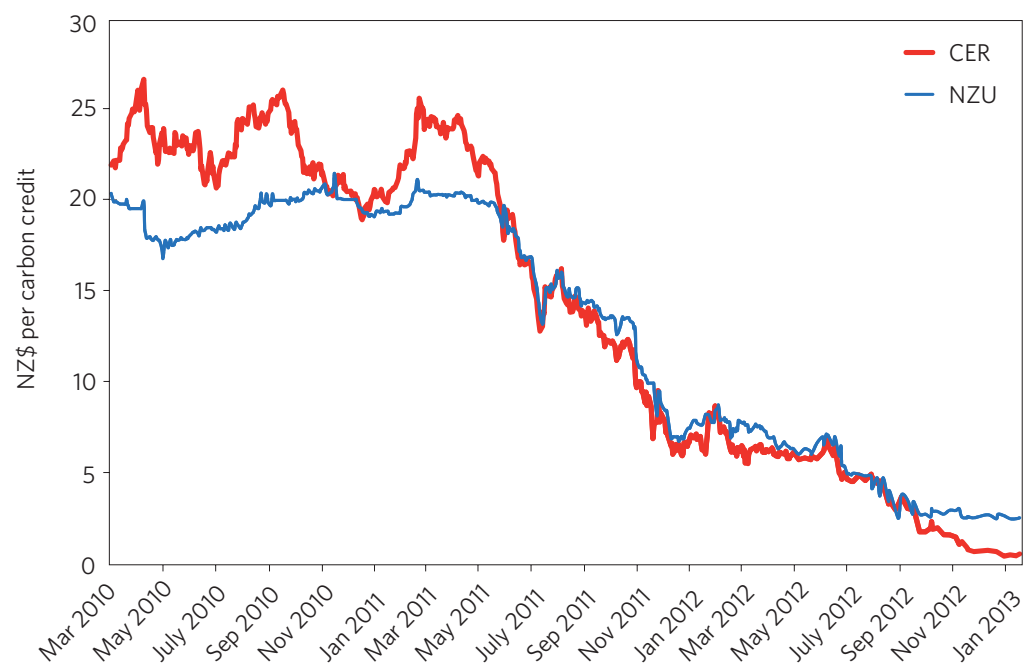

Figure 3 | The market price of NZ carbon credits on a given day (based on publicly available data). Figure reproduced with permission from ref. 7, (c) 2013 Future Science Limited.

Combined with international rules that exclude New Zealand from access to Kyoto units under the $\mathrm{CP} 2$, the government's position in international negotiations will inevitably change the dynamics of the domestic market. Although the country's disconnection from the international market is likely to increase demand for NZUs and provide incentives for afforestation and deter deforestation (for example, in the 2020s, when many managed forests are due to be harvested), the supply of additional NZUs through an auction mechanism will be needed. These issues, among others, support the idea of setting up a long-term price signal to encourage climate mitigation investments. This is consistent with the longterm 'economic resilience' objective of the NZ ETS, which includes incentivizing low-carbon technologies. In any event, an immediate halt to the flow of cheap Kyoto units remains a huge political battle.

It is clear that the NZ ETS is in need of improvements, and it is very likely that politics will decide the future of the NZ carbon market. National elections are due to be held in 2014 and, unlike Australia - where the new Liberal National coalition government dismantled the 'Climate Commission' and plans to scrap the carbon pricing mechanism - a change of government in New Zealand could see the implementation of new policy measures designed to increase the scheme's effectiveness and integrity. The major NZ opposition parties have been heavily critical of the 2012 amendments to the scheme, the lack of domestic effort, low carbon prices and the withdrawal from CP2. However, any meaningful reform will have to deal with inescapable policy trade-offs and may require the (bipartisan) political compromises found in climate policy.

Luis Mundaca* and Jessika Luth Richter are at the International Institute for Industrial Environmental Economics, Lund University, Tegnérsplatsen 4, 22100 Lund, Sweden.

*e-mail: luis.mundaca@iiiee.lu.se

References

1. New Zealand Emission Unit Register (Environmental Protection Authority, 2013); http://www.eur.govt.nz

2. Renowden, G. $100 \%$ useless: NZ government announces pathetic 5\% emissions target. Hot Topic (16 August 2013); http://go.nature.com/yFUoGc

3. Government Emission Target for 2020 Inadequate (Victoria University of Wellington, 2013); http://go.nature.com/HYidvf

4. Groser, T. New Zealand commits to 2020 climate change target. Beehive (New Zealand Government, 2013); http://go.nature.com/6k8uYn

5. New Zealand's Net Position under the Kyoto Protocol (Ministry for the Environment, 2013); http://go.nature.com/1W5Osg

6. Emission Trading Scheme Review Panel Doing New Zealand's Fair Share: Emissions Trading Scheme Review 2011 Final Report (Ministry for the Environment, 2011).

7. Luth Richter, J. \& Mundaca, L. Carbon Manage. 4, 423-438 (2013).

8. NZ ETS 2011 - Facts and Figures (Ministry for the Environment, 2012); http://go.nature.com/LLn63v

9. NZ ETS 2012 - Facts and Figures (Ministry for the Environment 2013); http://go.nature.com/7BauGH

10. Carbon CommTrade (OM Financial Limited, 2013); https://www.commtrade.co.nz

\title{
COMMENTARY:
}

\section{Carbon tax needs thresholds to reach its full potential}

\author{
John C. V. Pezzey and Frank Jotzo
}

The political opportunities for implementing a carbon tax high enough to induce large emission cuts will be better if at first the tax is charged on the difference between emissions and fixed thresholds, rather than on all emissions as is now practised.

\footnotetext{
the here is much fresh interest in national climate policies, despite the gridlock in international climate negotiations ${ }^{1}$. Of the two highest greenhouse gas ('carbon') emitters, China
}

has signalled its intention to introduce carbon pricing ${ }^{2}-$ a carbon tax and/or carbon (emissions) trading scheme and the USA is taking a regulatory route after earlier efforts to implement a trading scheme failed ${ }^{3}$. Pricing carbon emissions is widely accepted as being far cheaper for countries overall than regulation ${ }^{4}$, but a 'high' global price in the order of US $\$ 50$ per tonne of carbon dioxide 


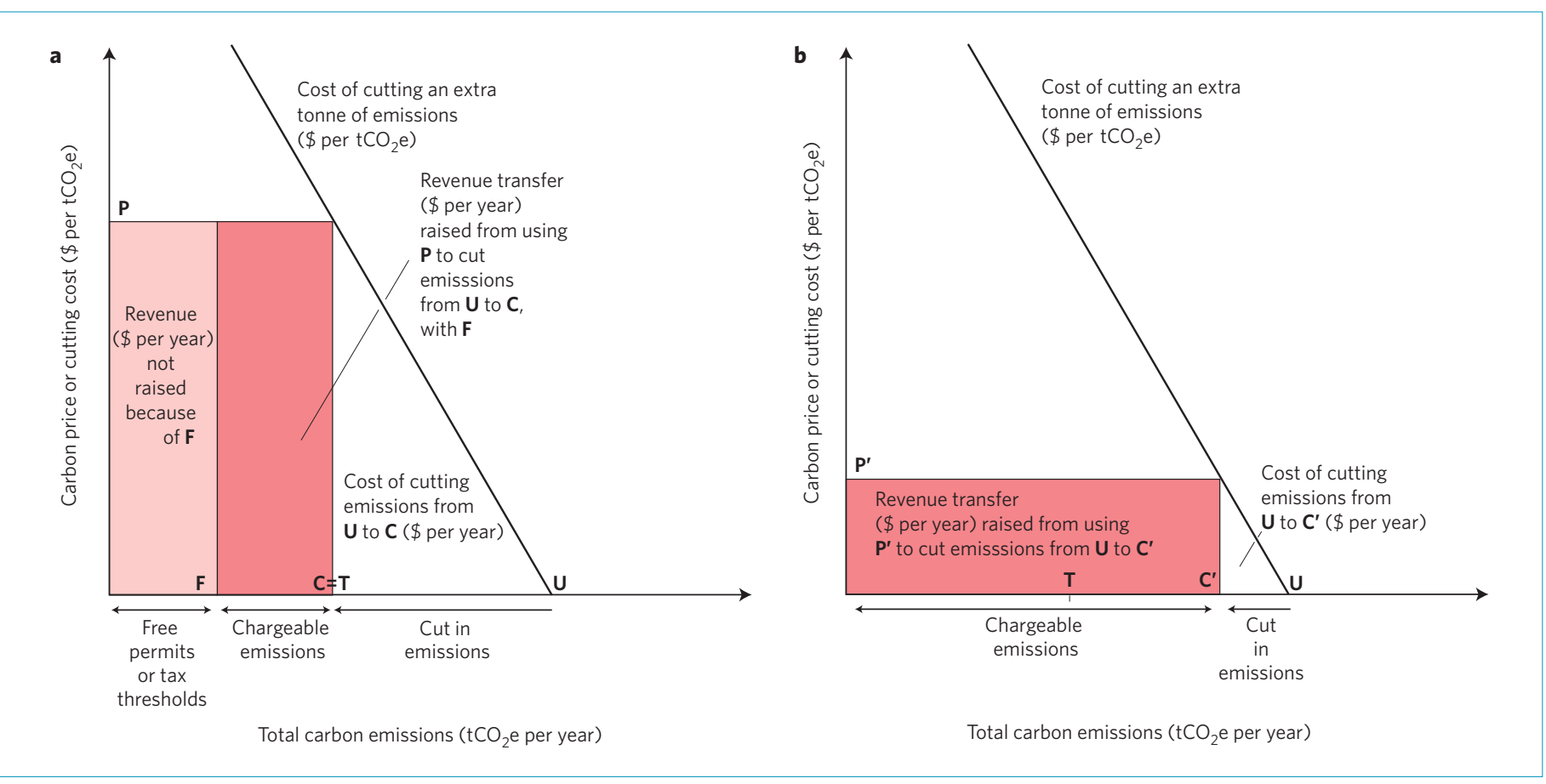

Figure 1 | A simplified illustration of how free carbon can enable a higher carbon price without increasing revenue. $\mathbf{a}$, Charging a price $\mathbf{P}$ on all carbon emissions that is high enough to achieve large cuts, from uncontrolled carbon $\mathbf{U}$ to controlled carbon $\mathbf{C}$ equalling target $\mathbf{T}$, typically yields a politically unacceptable level of revenue (pink plus red areas $=\mathbf{P} \times \mathbf{C}$ ). Revenue can be lowered to an acceptable level (red area only $=\mathbf{P \times}(\mathbf{C}-\mathbf{F})$ ) by granting free carbon $\mathbf{F}$. $\mathbf{b}$. With no free carbon, only a low price $\mathbf{P}^{\prime}$ can be charged, so controlled carbon $\mathbf{C}^{\prime}$ greatly exceeds the target, if revenue (red area $=\mathbf{P}^{\prime} \times \mathbf{C}^{\prime}$ ) is to stay the same (the graphs are drawn so that the two red areas are equal). The illustration is simplified because it ignores the likely fall in revenue from other types of taxes not related to carbon and rise in deadweight loss caused by a carbon price ${ }^{10}$, effects that would be stronger under the higher price in Fig. 1a.

equivalent $\left(\mathrm{tCO}_{2} \mathrm{e}\right)$ is still needed to induce significant cuts in emissions, with this price rising steeply as global control is delayed ${ }^{5}$.

Taxing rather than trading carbon has the advantage of creating a stable price ${ }^{4}$, while not undermining other carbon control efforts that have a role where carbon pricing is impossible or ineffective ${ }^{6}$. But as we show later, a key problem is that charging anything near US $\$ 50$ per $\mathrm{tCO}_{2}$ e on all emissions will raise far more revenue than has been acceptable in existing tax or trading schemes. This has been a reason to avoid imposing large burdens on carbon-intensive producers in the jurisdictions that favour carbon trading, carbon taxation with low tax rates and many exemptions, and/or regulation ${ }^{4,7,8}$.

There are many other factors important in policy debates about carbon taxation, including its environmental benefit and costeffectiveness ${ }^{9}$, and its possible distributional inequity (higher relative impact on poor households $)^{4,10}$. But carbon-intensive industries are highly concentrated, and thus can and do lobby powerfully ${ }^{11}$ (if often indirectly) for their interests. Achieving beneficial revenue neutrality - by recycling all the revenue in ways that improve economic efficiency and equity - will improve carbon taxation's broader political appeal, but will not relieve lobbying pressure as much as raising less revenue initially. Ignoring this regrettable reality has arguably made 'high', environmentally desirable carbon taxes politically much less feasible.

Yet the revenue problem can be avoided by abandoning the economically desirable but politically stifling presumption that a tax should be charged on every unit of emissions. Instead, governments can use a long-established idea they have so far ignored almost everywhere, by giving 'free carbon' as tax thresholds. These are essentially equivalent (symmetric) to free permits or allowances in carbon trading schemes, and work somewhat like income-tax thresholds. Emitters are charged tax only on the difference between their actual emissions and the emission thresholds they have been given, so the tax rate can in principle be as high as required, without raising and transferring politically unacceptable amounts of revenue from emitters to governments ${ }^{12-14}$.

But neither should revenue be deficient: as we explain below, it is needed to improve both distributional equity (itself worsened by free carbon) and economic efficiency. So for either tax or trading, free carbon should be limited, and ideally only a transitional measure. In summary, we argue that to make a high enough carbon price politically more acceptable, limited thresholds should be considered, in combination with beneficial revenue-recycling, whenever carbon taxation is proposed - just as some free permits are recognized as a pragmatic, politically important part of the introduction of carbon trading ${ }^{15}$.

\section{How free carbon works}

Both tax and trading can use free carbon to impose a higher carbon price without increasing the revenue raised by a pricing scheme, as shown in a simplified way in Fig. 1. In Fig. 1a the total net revenue transferred from emitters to the government is:

$$
\begin{aligned}
& \text { Revenue (\$ per year) } \\
& =\text { Price of carbon }\left(\$ \text { per } \mathrm{tCO}_{2} \mathrm{e}\right) \\
& \quad \times(\text { Controlled carbon } \\
& \quad \text {-Free carbon })\left(\mathrm{tCO}_{2} \mathrm{e} \text { per year }\right)
\end{aligned}
$$

with free carbon being some fixed level in $\mathrm{tCO}_{2}$ e per year. If this revenue is some maximum politically acceptable amount, then without free carbon only a lower carbon price and emissions cut are possible (Fig. 1b).

Large, carbon-intensive companies such as electricity generators and steelmakers have both a strong motive and the ability to 
ANYLAND GOVERNMENT • THE TREASURY

\title{
CARBON TAX THRESHOLD for 5,000 tonnes of $\mathrm{CO}_{2}$ equivalent
}

\author{
The Anyland Government will pay the bearer on \\ 1 July 2014 a sum equal to 5,000 tonnes, multiplied by \\ the $\mathrm{CO}_{2}$ tax rate in $\$$ per tonne set by the Anyland \\ Treasury for the financial year starting on that date.
}

\section{This threshold no. AGCTT00001 is tradable}

Figure 2 | A notional illustration of a carbon tax threshold treated as a property right, and therefore tradable.

lobby politically ${ }^{11}$ for more free carbon. But households, the final consumers of carbonintensive goods, ultimately bear most of the cost of emission control because companies pass through most of it as higher energy prices $^{16}$. These can hit poor households disproportionately hard ${ }^{17}$, and as evident from the US debate ${ }^{18}$ and the Australian carbon pricing mechanism ${ }^{19}$, form another major political problem with carbon pricing. Governments thus need to keep free carbon low enough (hence revenue high enough) to fund fiscal assistance to households, such as higher welfare payments. Moreover, because of cost passthrough, carbon-intensive companies do not need much free carbon (less than 15\% of total permits in one recent US study ${ }^{16}$ ) to prevent losses of profits.

Giving less free carbon also enables more efficiency-enhancing revenue recycling, such as lowering existing, distortionary tax rates ('environmental/ ecological tax reform ${ }^{20,21}$ ), which may boost support from businesses ${ }^{22}$, and supporting low-carbon technologies. Finally, raising more carbon revenue may be preferable to other ways of cutting budget deficits ${ }^{22}$.

Free carbon thus plays a key role in balancing opposing political and economic interests, a role widely fulfilled in carbon trading by free permits. Yet the academic literature generally ignores carbon tax thresholds ${ }^{1,22}$ or mentions them only in passing ${ }^{4,10,15}$. They remain legally and institutionally undeveloped, and policymakers have so far overlooked thresholds when considering carbon taxes.

\section{Free carbon design issues}

Free carbon is not a panacea that makes carbon pricing painless. Even with the overall costs of cutting emissions (the white triangles labelled in Fig. 1) minimized by pricing and revenues lowered by using thresholds, a carbon tax anywhere near US $\$ 50$ per $\mathrm{tCO}_{2}$ e may be politically infeasible in many countries, precisely because it would trigger the economic shifts needed for large emission cuts.

Also, thresholds inevitably raise other, still contentious issues. Governments must choose the duration and economy-wide total of thresholds, and their allocation among emitters and other stakeholders. But these very issues have been dealt with for free permits, because of their basic symmetry with thresholds ${ }^{12-14}$ (see section S1 of the Supplementary Information for details). The threshold or free permit total is particularly important, as every dollar given to industry is unavailable for beneficial recycling. There is, however, no universal rule for the maximum acceptable amount of carbon revenue, or politically necessary level of free carbon: it depends on the economic and political context, and can decrease over time. For example, most carbon trading schemes initially give the majority of permits for free, but the EU scheme has moved from initially $95-90 \%$ free allocations ${ }^{23}$ to about $60 \%$ now $^{24}$. The Australian scheme initially gave about $50 \%$ free permits, but has provisions to reduce free carbon over time ${ }^{19}$.

However, as tax thresholds have been neglected by policymakers, design issues peculiar to thresholds but irrelevant to free permits remain barely explored. One such issue is that for thresholds not to dilute any control incentives, they would need to take the form of tradable property rights, as illustrated in Fig. 2. However, it may be simpler legally and administratively, if less cost-effective, to instead create thresholds as non-tradable entitlements similar to personal income-tax thresholds. A second problem, pivotal in the failure to introduce a European carbon-energy $\operatorname{tax}^{23}$ in the 1990s, is which jurisdictional levels have the power to tax. Both of these legal issues could be avoided by using a tax-like trading mechanism, such as permits with a fixed price as in Australia ${ }^{19}$, or trading subject to a price ceiling and floor close enough to form a tight price 'collar'25,26.

\section{Evidence from carbon pricing so far} In the current Australian carbon pricing scheme, which the newly elected Conservative government intends to repeal, permits have a government-determined 'fixed' price starting at $\mathrm{AU} \$ 23$ per $\mathrm{tCO}_{2} \mathrm{e}$ during the initial phase, effectively making a formal trading scheme a tax. Following lobbying pressure, about half of the potential revenue is initially not raised from emitters, by giving them free permits or cash. ${ }^{19}$ This sets an important precedent for how a threshold-like arrangement can help to win acceptance for a carbon tax-like scheme. Significantly different is South Africa's plan for partial exemptions from its carbon tax for some industries, with exemptions linked to controlled emissions, which would reduce the effective tax rate by up to $90 \%{ }^{27}$. By contrast, our carbon tax thresholds would leave the tax rate on each extra tonne of emissions undiminished.

Free carbon has been much used where it is institutionally accepted, namely in trading schemes. Of eleven such schemes enacted in eight countries, ten allocate high proportions, often over $90 \%$, of free permits $^{28}$. The exception - the US Regional Greenhouse Gas Initiative - until 2013 had an emissions target so unambitious that its price never exceeded US $\$ 3.5$ per $\mathrm{tCO}_{2} \mathrm{e}$ (ref. 29). Pilot carbon trading schemes in China are planning to allocate the large majority of permits for free ${ }^{30}$

By contrast, none of eleven tax schemes, mostly in Northern Europe, gives any partial exemptions (that is, thresholds) to emitters $^{31}$. Instead, many industrial sectors face much lower tax rates or get total exemptions, thus undermining the schemes' overall performance.

The importance of free carbon is also shown by the history of carbon pricing proposals. Free permits were important in the EU decision to adopt carbon trading rather than $\operatorname{tax}^{23}$. In 2005, the New Zealand 
government planned a carbon tax with no thresholds, many sectoral exemptions and all revenue recycled as lower existing taxes. A review scrapped the plan, with the unfairness and inefficiency of its exemptions given as the key reason ${ }^{32}$, and New Zealand now has a carbon trading scheme with ample free permits ${ }^{33}$. Lobbying by carbonintensive companies secured steep rises in free carbon during the early development of the Australian carbon pricing scheme in 2008-2009 ${ }^{34}$. The US administration's 2009 proposal to auction all permits in a trading scheme contrasted sharply with the $85 \%$ and $88 \%$ free permits recommended by subsequent Congressional bills ${ }^{35}$.

Last but perhaps most important, the highest net carbon pricing revenues achieved in practice are small fractions of either GDP or central government's revenue from all taxation, and are far below what an ambitious, 'high' price would yield if charged on all emissions. The highest carbon tax revenue raised so far, in the Netherlands, has been about $0.9 \%$ of GDP or $4 \%$ of central tax revenue; whereas in the EU as a whole, carbon trading revenue would now be roughly $0.1 \%$ of GDP or $0.5 \%$ of central tax revenue under typical 2008-2012 prices, or much less under the prices prevailing in 2013. Yet a global price of US\$50per $\mathrm{tCO}_{2} \mathrm{e}$ would initially, if charged on all current $\mathrm{CO}_{2}$ emissions with no decrease in emissions assumed, raise revenue worth about $2 \%$ of GDP or $12 \%$ of central tax revenue in the USA, and about $8 \%$ of GDP or $75 \%$ of central tax revenue in China (Supplementary Tables S1 and S2, with selected results illustrated in Fig. 3).

Increased perception of the urgent need to control global warming ${ }^{5}$ combined with budgetary deficits ${ }^{22}$ may gradually make using carbon pricing to raise revenue more acceptable, but reaching anywhere near such revenue levels seems politically implausible in the medium term. We conclude that for a carbon tax, or tax-like mechanism, to reach its full potential, its proponents need to consider including carefully designed thresholds to balance conflicting economic and political pressures on revenues. The need will be particularly acute in newly industrializing countries with high carbon intensity, including China, if they wish to introduce a 'high' carbon tax. Developing the tax threshold concept, and dropping the needless presumption that all emissions from each included source must be taxed, are thus urgent tasks for climate policymakers.

John C. V. Pezzey ${ }^{1 *}$ and Frank Jotzo $0^{2,3}$ are at ${ }^{1}$ Fenner School of Environment and Society, Australian National University, Canberra, Australian Capital Territory 0200, Australia, ${ }^{2}$ Crawford School of
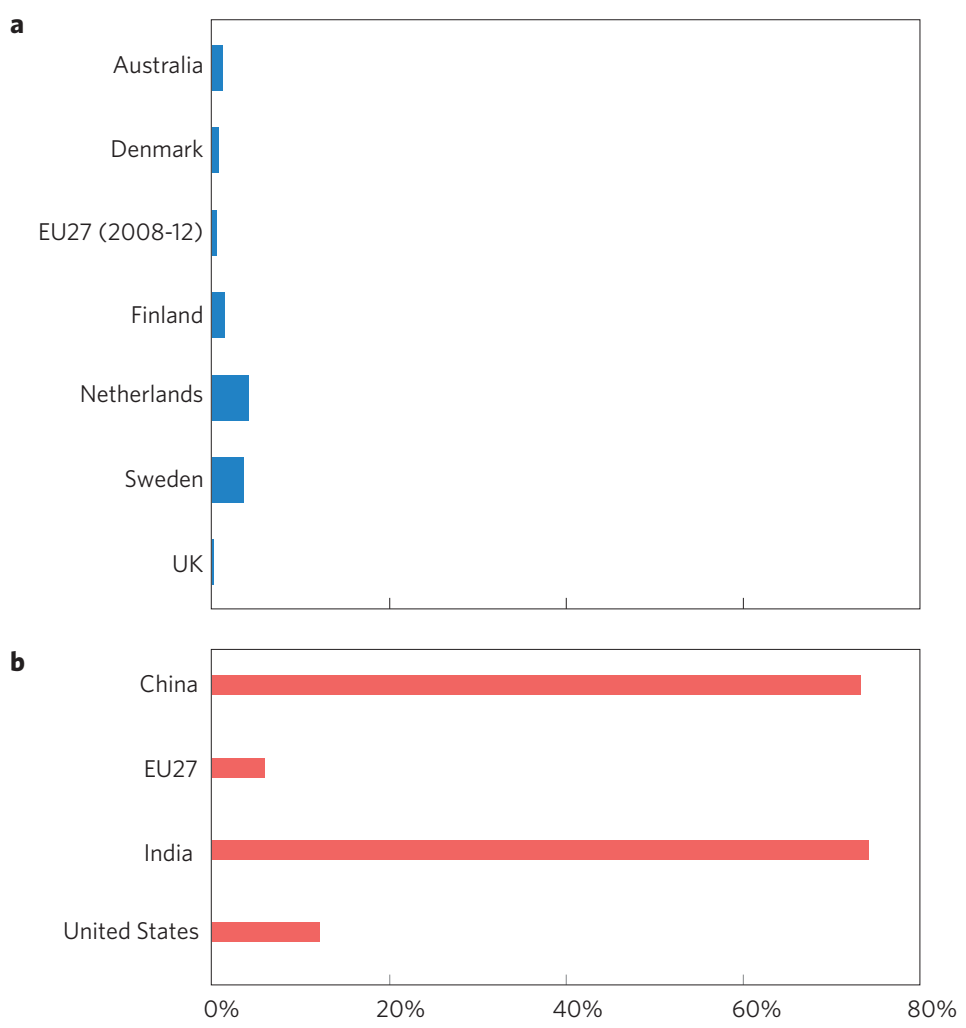

Figure 3 | Past and potential future carbon price revenues, as shares of central government tax revenue. a, Carbon pricing revenue as a share of central tax revenue over various time periods from 2003 onwards. b. Hypothetical revenue from a US\$50 per $\mathrm{tCO}_{2}$ e carbon price charged on all emissions, plotted as a proportion of central tax revenue. Data from Supplementary section S2.

Public Policy, Australian National University, Canberra, Australian Capital Territory 0200, Australia, ${ }^{3}$ Centre for European Economic Research, Mannheim 68161, Germany.

*e-mail: jack.pezzey@anu.edu.au

References

1. Victor, D. G. Global Warming Gridlock (Cambridge Univ. Press, 2011).

2. 12th Five-Year Plan (2011-15) (National People's Congress, 2010).

3. Burtraw, D. \& Woerman, M. US Status on Climate Change Mitigation Discussion Paper 12-48 (Resources for the Future, 2012).

4. Aldy, J. E., Krupnick, A. J., Newell, R. G., Parry, I. W. H. \& Pizer, W. A. J. Econ. Lit. 48, 903-934 (2010).

5. Rogelj, J., McCollum, D. L., Reisinger, A., Meinshausen, M. \& Riahi, K. Nature 493, 79-83 (2013).

6. Goulder, L. H. \& Stavins, R. N. Am. Econ. Rev. 101, 253-257 (2011).

7. Svendsen, G., Daugbjerg, C., Hjollund, L. \& Pedersen A. Energy Policy 29, 489-497 (2001)

8. Goulder, L. H. \& Parry, I. W. H. Rev. Environ. Econ. Policy 2, 152-174 (2008).

9. Baranzini, A. \& Carattini, S. in Global Environmental Change (ed. Freedman, B.) (Springer, 2013)

10. Metcalf, G. E. Rev. Environ. Econ. Policy 3, 63-83 (2009).

11. Olson, M. The Logic of Collective Action (Harvard Univ. Press, 1971).

12. Pezzey, J. Can. J. Econ. 25, 983-991 (1992).

13. Farrow, S. Econ. Lett. 49, 217-220 (1995).

14. Pezzey, J. C. V. Environ. Resour. Econ. 26, 329-342 (2003).

15. Stavins, R. N. Harvard Environ. Law Rev. 32, 293-371 (2008).

16. Goulder, L. H., Hafstead, M. A. C. \& Dworsky, M. S. J. Environ. Econ. Manage. 60, 161-181 (2010).

17. Grainger, C. A. \& Kolstad, C. D. Environ. Resour. Econ. 46, 359-376 (2010).

18. Gale, W. G., Brown, S. \& Fernando, S. Carbon Taxes as Part of the Fiscal Solution (Brookings Institution, 2013).

19. Jotzo, F. Nature Clim. Change 2, 475-476 (2012).

20. Pearce, D. W. Econ. J. 101, 938-948 (1991).
21. Baranzini, A., Goldemberg, J. \& Speck, S. Ecol. Econ. 32, 395-412 (2000)

22. Aldy, J. E. Oxford Energy Forum 91, 13-16 (2013).

23. Convery, F. J. Environ. Resour. Econ. 43, 391-412 (2009).

24. The EU Emissions Trading System (EU ETS) (EU, 2013).

25. McKibbin, W., Morris, A. \& Wilcoxen, P. in Climate Change Policy: Recommendations to Reach Consensus 26-34 (Brookings Institution, 2009).

26. Fell, H. \& Morgenstern, R. D. Environ. Resour. Econ. 47, 275-297 (2010)

27. Updated Carbon Tax Policy Paper (South African National Treasury, 2013); http://go.nature.com/9MCByu

28. Passey, R., Bailey, I., Twomey, P. \& MacGill, I. Energy Policy 48, 551-561 (2012).

29. Auction Results: Allowances Offered and Sold (Regional Greenhouse Gas Initiative, 2013); http://www.rggi.org/market/co2_auctions/results 30. Lo, A. Y. Nature Clim. Change, 2, 765-766 (2012).

31. Sumner, J., Bird, L. \& Dobos, H. Clim. Policy 11, $922-943$ (2011). 32. Climate Change - Review of Policy and Next Steps (New Zealand Climate Change Office, 2005); http://go.nature.com/91VDLi

33. Jiang, N., Sharp, B. \& Shen, M. New Zeal. Econ. Papers 43, 69-79 (2009).

34. Pezzey, J. C. V., Mazouz, S. \& Jotzo, F. Aust. J. Agr. Resour. Econ. 54, 185-202 (2010)

35. Comparison of the American Power Act (Kerry-Lieberman) and the American Clean Energy and Security Act (Waxman-Markey) (Pew Center, 2010)

Acknowledgements

We thank F. Convery, M. Grubb, S. Hatfield-Dodds, A. Morris, T. Sterner and D. Victor for helpful comments, and C. Hilliker for technical assistance with the figures.

Additional information

Supplementary Information is available in the online version of the paper. 